\title{
BIOMIMETICS: A SIMPLE FOUNDATION WILL LEAD TO NEW INSIGHT ABOUT PROCESS
}

\author{
S. JACOBS \\ Department of Integrative Biology, University of Guelph, Canada.
}

\begin{abstract}
From Bionics and Biomimetics to Biomimicry, these terms have been used to describe the transfer of knowledge from biology to other disciplines. They have been poorly defined and inappropriate uses are becoming more frequent. In addition, the organization of the framework for describing biological innovations is being developed in such a way as to reduce access to biological innovation. A need for clarification and the development of a rigorous method still exist. An analysis of the frequency of use of the terms associated with mimicking biological models reveals that biomimetics is more widely used than biomimicry, but it is unclear whether these terms are being used uniformly or accurately. The following definition of biomimetics is proposed: 'the study of biological functions, its forms, processes, and interactions for the purpose of solving analogous human problems', and it is suggested that biomimicry be reserved to describe sustainable biomimetics. Two case studies are presented on products widely claimed to be examples of biomimicry that do not meet the criteria for the definition of biomimetic presented here. They are discussed in the context of biological function. Biomimetic research activities are often organized into 'levels' - Shape, Process, and Ecosystem - suggesting a hierarchy. Here, it is proposed that these levels be referred to as 'types' nested within Function and be called: Form, Process, and Interaction. A classification system based upon the number of types of biomimetics that are incorporated into the innovation is also described. This simple framework will permit the study of biomimetic activity 'in the wild' as it currently exists so that it will better inform the development of a more rigorous process.

Keywords: Biomimetics, biomimicry, bionic, bio-inspiration, innovation inspired by nature.
\end{abstract}

\section{INTRODUCTION}

The entry into the Anthropocene epoch marks an important change in the drivers that are changing the environment [1]. Human activity now dominates those drivers, contributing significantly to the crossing of planetary boundaries where abrupt global change would no longer be preventable [2]. Curiously, the predominant pathway of economic and technological development remains largely unaltered by such threats [3]. Nature has evolved forms, processes, and interactions that, though they may be responsible for large-scale environmental paradigm shifts (i.e. photosynthesis), are not destructive to life. In fact, they have largely been associated with increasing biodiversity. The transfer of knowledge from the field of biology to other domains in human society will play a fundamental role in addressing the challenges that arise as these tipping points are reached.

With the usage in both the popular and scientific domains, biomimetics and biomimicry are defined in various ways throughout the literature. To this end, confusion regarding the delineation of the field still exists and though some attempts have been made to clarify the terms and restructure the theoretical foundation of biomimetic activity [4-7], the discussion continues to be contained within specific disciplines of research. Vincent et al. [5] recognize that biomimetics is widely regarded as being synonymous with biomimicry, biomimesis, biognosis and similar to biologically inspired design. Since the 1990s, biomimetics (in the form biomimicry) has become associated with the 'green' movement and of increasing scientific interest in conjunction with a rise in patents referencing the field [8]. These symptoms suggest a problem recognized as early as the 1960s in biomimetics with respect to development in interdisciplinary areas of research: developing a clear interface cannot be done by uni-disciplinarily trained people [9] and the framework of the field must be derived from the discipline of origin rather than applying the framework of another. If frameworks from, for 
example, engineering are applied to biology, the potential for missing the characterization of disruptive innovation is greatly increased. Traditional disciplinary approaches are hindering the practice of biomimetics and this, in combination with a lack of clearly defined methodologies, has generated considerable scepticism with respect to the future potential of this field [4].

A lack of clarity in the definitions and boundaries between the different technical fields taking inspiration from the aspects of biology leads to confusion about the goals of the innovative process. This situation is leading to the inappropriate use of the term in advertising and promotion and contributing to the 'greenwashing' of an emerging interdisciplinary scientific field [8]. Studying the emergence of this field and addressing fundamental weaknesses will strengthen the practice of biomimetics and serve as a guide over the slump that many feel exists.

The concept of learning from nature is not new [10,11]; examples are found in traditional knowledge and in the works of artists and engineers from previous centuries. The work of Leonardo da Vinci (1452-1519) is one of history's best documented and most cited early modern examples. However, the concept of biomimetics as a scientific field of research was formally introduced by the American biophysicist Otto Schmitt in the late 1950s, who may have coined the term a decade later [12]. Designed to mimic the propagation of electrical energy within the nervous system of cephalopods, Schmitt invented the Schmitt trigger in 1934 and he is credited with having used the term biomimetics regularly to describe this work though he never officially defined it [12]. The Oxford English Dictionary attributes the first use of the term biomimetic to 1960 with the following explanation of the rather unusual circumstances:

The Oxford English Dictionary ascribes the first use of the adjective biomimetic to the index (emphasis added) for volume 132 of Science, published in December 1960 (Annon. [13]). The index itself refers to two articles published two months apart, each proposing a new naming convention for devices which simulate biological functions. The author of the first paper advocates the use of the suffix -mime for such devices (Van Bergeijk [14]), and it is this suggestion that the compiler of the index extrapolates into the adjective biomimetic for the index; the term does not appear in either of the papers referred to (Craft, OED Editor, Pers. Comm.).

It is only in 1974 that biomimetics was first defined in the Merriam-Webster Dictionary as: 'The study of the formation, structure, or function of biologically produced substances and materials (as enzymes or silk) and biological mechanisms and processes (as protein synthesis or photosynthesis) especially for the purpose of synthesizing similar products by artificial mechanisms which mimic natural ones'. In this early definition of biomimetics, the emphasis is on processes and synthesis, associated more with chemistry than the other sciences and at limited scale.

The coining of a similar term bionics is written to have occurred also in 1960 by Jack Steele while working at Wright-Patterson Air Force Base in Dayton, Ohio [5, 11, 15, 16] (also attributes Biomimetics to Steele, or in 1958 by Steele Vogel [17]). Though the proceedings from this conference do not contain a precise definition by Steele, it does contain valuable insight into the potential challenges that research in biomimetics might encounter $[9,18,19]$. Bionics entered the MerriamWebster dictionary in 1960 as 'a science concerned with the application of data about the functioning of biological systems to the solution of engineering problems'.

In the early definitions of both biomimetics and bionics, sustainability and green-products were not considered; focus was placed on product development through interdisciplinary cooperation between engineering and biology (and mathematics [9]). It is not until much later that sustainability criteria based upon what are understood to be principles common to biological systems (i.e. integrated, multifunctional, energy saving, recirculating, network construction) are introduced 
as part of the principles of bionics (Nachtigall [20] as translated in Gruber [6]), in conjunction with a switch to using the term biomimicry in the English-speaking world.

If in its early use, the term bionic was not especially linked to the context of robotics and artificial intelligence, it certainly adopted this connotation in English-speaking realms when Martin Caidin wrote his 1972 novel Cyborg which resulted in the 1974 television series 'The Six Million Dollar Man'. Bionic then became widely associated with 'having or denoting an artificial, typically electromechanical, body part or parts' [21]. Because the term bionic implied supernatural strength, the scientific community in English-speaking countries largely abandoned it [15]. But bionic is still widely used in the field of medicine, robotics, and artificial intelligence and is the term of choice among German-speaking countries (bionik).

The usage of the word 'biomimicry' does not begin until the 1990s (Fig. 1) and when used prior to this, even in the scientific literature, it is done so without clear definition (i.e. [22]). The term was widely popularized by Janine Benyus in her 1997 book Biomimicry: Innovation Inspired by Nature. Here, biomimicry is defined as a 'new science that studies nature's models and then imitates or takes inspiration from these designs and processes to solve human problems' and emphasis is placed upon sustainability as a core objective of biomimicry. Ataide [22] refers to biomimicry as: 'the discipline of applying nature's principles to solve human problems'. The author is referring specifically to a list of descriptors intended to represent the principles by which nature operates developed by Biomimicry 3.8. Pedersen Zari [7] defines biomimicry as: "where flora, fauna or entire ecosystems are emulated as a basis for design', and Nieuwenhuis and Lammgard [23] define it as: 'the attempt to mimic natural processes in man-made environments'. These last two definitions clearly reflect the field of research in which the authors are engaged (architecture and industrial

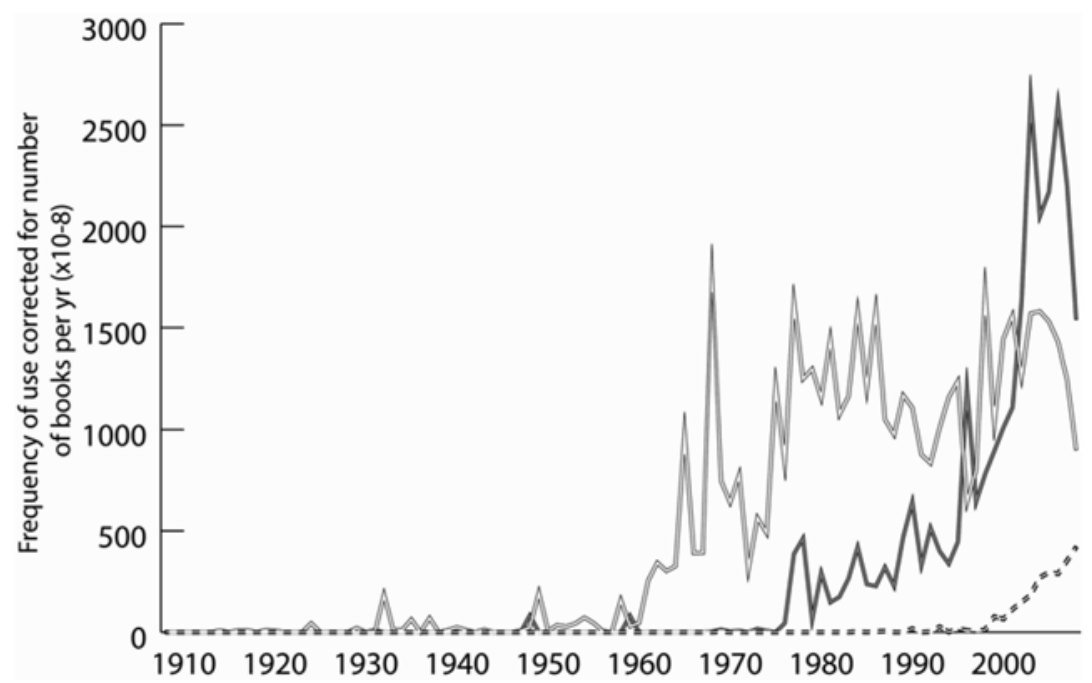

Figure 1: Frequency of the use of words to describe biomimetic (and related) activities/products using Google's ngram viewer analysis of 5.2 million books. $($ Bionic $=$ white, Biomimetic $=$ dark grey, Biomimicry = black dashed.) These data were adapted from the database with case sensitivities and plural forms combined into one value. The data are normalized for number of books per year. 
ecology, respectively) while many definitions refer to the 'attempt' rather than the result. Gleich et al. [4] define biomimetics as 'the attempt to learn from nature; it deals with the development of innovations on the basis of investigation of natural, evolutionarily optimized biological structures, functions, processes, and systems'. Dargent [16] recently defined it as: 'an interdisciplinary field that takes inspiration from nature to design innovative products and processes'. These are the least problematic of those existing definitions, though defining biomimetics as an 'attempt' rather than a process, methodology, or its result and the assumption of evolutionary optimization are problematic while the latter remains limited in scope. Gleich et al. [4] acknowledge the difficulty associated with developing a clear definition in light of the increasing number of users associated with biomimetic activity and suggest a preference for creating a mission statement (linked to sustainability) rather than a precise definition.

Most recently, the ISO/CD 18458 (Biomimetics - Terminology, concepts, and methodology) has developed a definition of biomimetics (currently in draft form; pers. comm.): 'interdisciplinary cooperation of biology and technology or other fields of innovation with the goal of solving practical problems through the abstraction, transfer, and application of knowledge gained from biological systems', which highlights the fundamental steps in knowledge transfer but minimizes the importance of function.

The definition of biomimicry by Benyus [24] more accurately reflects the intention of biomimet$i c s$, though it is largely focussed on 'sustainable' biomimetic advancements. In light of this and after consideration of studies in which the use of biomimicry is reported (i.e. [22]), there is need for a revision of the definitions (Table 1) and to clearly identify the differences between each term.

A review of the frequency of the use of the words associated with biomimetics using Google's Ngram Viewer reveals that biomimetic (Biomimetic, biomimetics, and Biomimetics) is more widely used than biomimicry in the literature, with both definitions exhibiting a peak use after 2000 (Fig. 1). Though it is not possible to verify whether these terms are used appropriately, and understanding that this search is from a collection that represents only a limited number of the printed material ever produced, certain interesting trends are found. Bionic (Bionics, bionic, and bionics) is also used more than biomimicry and the frequency of biomimetics is almost double that of bionics.

As the frequency of biomimicry and its derivatives increases, the frequency of the use of bionic and biomimetic and their derivatives decrease (Fig. 1). It is likely that biomimicry, in addition to being used by the 'environmental' lobby, has also been used by those outside of the lobby due to the effective publicity campaigns.

Taking into account the historical uses of the definition, Table 1 presents the proposed refinements. Biomimetics is defined as:

The study of biological functions, the forms, processes, and interactions for the purpose of solving analogous human problems.

Future research will allow us to investigate the usage of each of the terms (and quite possibly more) used in the development of biomimetic technologies. Do these technologies mimic biological function according to the proposed definition? Are biomimetic technologies also sustainable technologies? Are biomimetic technologies that are also sustainable more commonly described as being acts of biomimicry? These types of questions are informative in a field where 'access' to knowledge is of such fundamental importance.

The proposed definition emphasizes the importance of function. Mimicking a biological function is the entrance to biomimetic innovation; it is not simply one of the categories or levels or aspects to consider. Indeed, human innovation outside of the context of mimicking the biological function is 
Table 1: Current definitions and proposed refinements of terms.

\begin{tabular}{|c|c|c|c|}
\hline Term & Definition & Revised definition & Scope \\
\hline Biomimetics & $\begin{array}{l}\text { 'Modelled on or resembling } \\
\text { a natural biological material, } \\
\text { process, etc.; (of a synthetic } \\
\text { method) that mimics } \\
\text { biochemical processes' } \\
\text { (OED 1960) }\end{array}$ & $\begin{array}{l}\text { The study of biological } \\
\text { functions, the forms, } \\
\text { processes, and interactions } \\
\text { for the purpose of solving } \\
\text { analogous human problems }\end{array}$ & $\begin{array}{l}\text { Wide: } \\
\text { Engineering } \\
\text { Medicine } \\
\text { Information } \\
\text { Technology } \\
\text { Economics } \\
\text { Systems science }\end{array}$ \\
\hline Bionics & $\begin{array}{l}\text { 'The science of systems } \\
\text { which have some function } \\
\text { copied from nature, or which } \\
\text { represent characteristics of } \\
\text { natural systems or their } \\
\text { analogues' [20] }\end{array}$ & $\begin{array}{l}\text { Biomimetic approach } \\
\text { to augment or replace a } \\
\text { particular biological } \\
\text { function with electronic } \\
\text { or electromechanical } \\
\text { components }\end{array}$ & $\begin{array}{l}\text { Limited: } \\
\text { Engineering } \\
\text { Medicine } \\
\text { Cybernetics }\end{array}$ \\
\hline Biomimicry & $\begin{array}{l}\text { 'New science that studies } \\
\text { nature's models and then } \\
\text { imitates or takes inspiration } \\
\text { from these designs and } \\
\text { processes to solve human } \\
\text { problems' [24] }\end{array}$ & $\begin{array}{l}\text { Biomimetics for the } \\
\text { purpose of developing } \\
\text { sustainable innovations; } \\
\text { sustainable biomimetics }\end{array}$ & $\begin{array}{l}\text { Limited: } \\
\text { Research and } \\
\text { development } \\
\text { with a goal of } \\
\text { sustainable } \\
\text { development }\end{array}$ \\
\hline
\end{tabular}

simply an art made of either biological material or a biological aesthetic. Theories of living systems acknowledge the importance of function: it is what makes biology different from other natural sciences $[25,26]$. A function in living and non-living systems can be the result of different combinations of forms (or structures), processes (or synthesis, or behaviours), and interactions (or systems). Achieving the function in biomimetics is the desired result - the target of the innovative work- but it is also the action or the service provided as a result of a specific form (i.e. a protein), a process (i.e. chemical cascade), or an interaction (i.e. mutualism; but also including the emergent properties of systems).

In the context of the above definition, two types of misuses occur. The first is confusion between biomimetics (or past uses of biomimicry) and bio-assistance or bio-utilization. The second is confusion between biomimetics (or past uses of biomimicry) and simply copying nature without mimicking function.

\section{CASE: BIO-ASSISTANCE}

Bio-assisted technology incorporates living molecules, cells, tissues, organs, individuals in some aspect of the product. It is not mimicking the process, system structure or types of interactions to solve a human problem but rather it uses biological parts that already exist in nature to perform a biological function. This distinction has important consequences for theoretical development and classification schemes. 
An example of mis-classification comes from Ataide [22]. Biolytixwater, an Australian company, has developed a wastewater treatment system to turn household black and grey water into irrigationquality water. Essentially, they have housed the organisms and materials of the forest that carry out natural filtration and cleaning processes. The benefits of this organic filter include decreased costs of servicing, elimination of aeration, no pump-outs, and decreased energy consumption by up to $90 \%$. As exciting as this product appears to be with respect to the promotion of the principles of sustainable development, this is a clear case of bio-assisted technology rather than biomimetics. Instead of designing and producing a technology that provides the same service as the forest floor, Biolytixwater has taken pieces of the actual forest floor to do the job. In fact, they have shown that using biomimetics (by creating a forest floor replacement widget) would likely generate more waste and require more energy. Bio-assistance is the preferred sustainable solution but simply using living materials directly from nature even for environmental reasons does not fall within the scope of biomimetics. It is interesting to note that the company Biolytixwater makes no claim in any published material of having practiced biomimetics or biomimicry.

This case, however, could be classified as mimicking the function of a forest floor. Because forest floors provide the function of cleaning contaminated water in natural systems, an argument could be made for having mimicked this biological model but only at the simple entry point of function. Claims of having mimicked only function, however, are rather weak because, equally, it could be that a bulldozer mimics the function of a bird's feet when it kicks up stones to make a shallow depression.

\section{CASE: FORGETTING FUNCTION}

Copying something observed in nature is not sufficient to be claimed under the scope of biomimetics. If this were so, a painter could paint a house green and call it biomimetic because she was inspired by the colour of a forest canopy. Nature's innovation of photosynthetic organelles is not being mimicked and, therefore, painting a house green for aesthetic purposes is not biomimetic. To call it biomimetic, our painter would need to paint a house with energy-producing paint whether it is green or otherwise. Though the green house may seem like an exaggerated example, this misuse of the biomimetic label does exist in alarming frequency. Widely celebrated as a champion of biomimetics (or biomimicry), Interface flooring represents one such example. In 2000, InterfaceFlor announced the launch of their first biomimicry-based flooring system, Entropy. This was followed up in 2003 with the launch of i2 flooring, also heralded as an example of biomimetic technology [27].

It is claimed that Entropy and i 2 mimic the random design of a forest floor [27]. The flooring tiles vary in colour and individual pattern and do not need to be laid in a specific sequence. The company designers claim that they asked themselves 'how would nature design a floor tile?' [28]. The cost savings and reduced environmental impact of this product is, without question, significant; variations in colour and pattern allow for minimal storage requirements because each product line and tiles can be replaced individually. However, forest floors have not produced a flooring system for the purposes of walking upon or decorating the ecosystem. InterfaceFlor designers did not ask: 'has nature designed a floor tile?'

The function of a forest floor is not aesthetic, nor is it to provide a surface upon which to walk. Forest floors act as a reservoir for nutrients in the form of organic material and consequently regulate many processes throughout the ecosystem $[28,29]$. In addition, the perceived random nature of the forest floor aesthetic is a consequence of the processes associated with its formation and function, just as the colour green is a consequence of the presence of chlorophyll within plant cells. In fact, forest species dispersion is not at all random, it is patchy [30,31], and the consequent composition of the floor beneath is also, therefore, patchy [32]. Furthermore, random dispersions are the least 
common form and the most difficult to identify. This has led some scientists to question whether it is in fact a type of dispersion at all (Solomon et al. [32] more readily accessible: Wikipedia). InterfaceFlor is painting the floor green as far as their participation in biomimetic activity is concerned.

Though marketing persons may be quick to adopt the label biomimicry because of its 'green' associations, there must be a clear separation between what is biomimetic and what is environmentally friendly(ier), or sustainable. The importance of sustainable production or other areas of research reduce environmental impact is not being diminished. Rather, it is important to note that these goals can also be attained in ways other than biomimetics (e.g. bio-assistance) and, for the development of the field of biomimetic research, it is important to understand the potential and boundaries that exist while recognizing that biomimetic research conducted under the principles of sustainability and environmental awareness is an important goal.

\section{LEVELS AND TYPES - DEVELOPING A COMMON LANGUAGE}

Several references to three 'levels' of biomimicry are available online and in the non-peer reviewed literature (i.e. Biomimicry 3.8, Biomimicry Europa, etc.), and one classification system was presented at a conference [7]. In all cases, biomimetic research activity is organized into 'levels' suggesting a hierarchy in which the first level is not as desirable, or perhaps as complicated as level 2 or 3.

Pedersen Zari's [7] classification is intricate with three levels each containing five dimensions. The three levels are Organism, Behaviour, and Ecosystem and a comprehensive list of possible outcomes (the product) are presented. The results of this thought experiment produced some delightful examples. The author presents five dimensions for each: Form, Material, Construction, Process, and Function. In some cases, there is confusion with respect to the biological level of organization at which the product is made and the author acknowledges that there is some redundancy in the scheme presented [7]. Irrespective of these small hurdles, this effort is indeed lacking in the biomimetic literature and though the Pedersen Zari scheme was developed for use within the field of architecture, it is an acknowledgement of the need for a taxonomy; a common language and classification system will facilitate research into (and the 'quantification' of) the process of knowledge transfer for the purposes of biomimetic activity.

The three levels most commonly described are shape, process, and ecosystem [33]. Descriptions of these levels and the use of the word 'level' suggest that there is a hierarchy to which biomimetics can be conducted, that working at the ecosystem level is somehow more desirable or complex than working at the level of shape. This likely originates from only a basic understanding of the biological levels of organization and the interchange between the words ecosystem and system (used synonymously with interaction) in classification schemes that consequently suggests that mimicking something at the interaction level necessitates that one be guided by the characteristics of an ecosystem (which includes the word 'interaction' in its definition) and that this is somehow superior to (or more sustainable than) mimicking other 'lesser' aspects. Because biomimetics takes its model from biology, we may not be able to include mimicking aspects of ecosystems (because they include nonliving components), except to mimic the interactions between the living and the non-living, perhaps. We can, however, mimic aspects of Communities (the assemblage of living components within an ecosystem) and certainly from interactions among living things at other levels of biological organization. Most importantly, interaction-type biomimetics is not obviously any 'better' than the other types, nor is it necessarily more sustainable. Because the overlaying motivator for engaging in biomimetic research is to mimic function linked to specific goals or effects, mimicking something that has no function would be of no human use apart from, perhaps, the aesthetic. Therefore, all the examples of biomimetics that exist, from Velcro, to STO Corp paint, should be mimicking some 


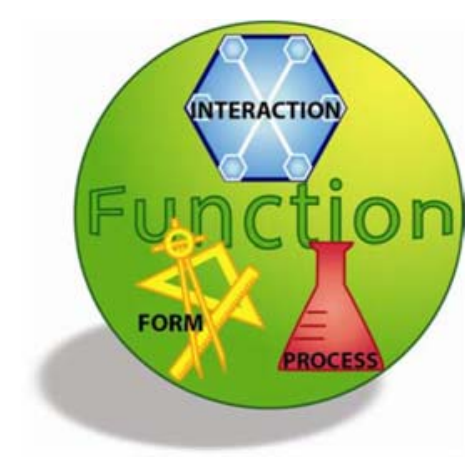

Figure 2: The types of biomimetics; Form, Process, and Interaction are nested within Function.

function( $(s)$ in nature. Within biological systems, function can be achieved through form, process, or interaction. Therefore, it is possible for a biomimetic product, mimicking a biological function, to achieve that function by mimicking form, process, or interaction of the biological model. These types are, therefore, nested within function (Fig. 2).

If we were to simply mimic the function of something found in nature but not the way in which it accomplishes that function, then the type of biomimetic activity would be simply characterized as Function. In most cases, it would be trivial to practice biomimetics at the Function type only, though it is possible that a new biological function be discovered and this type will likely become of greater importance as we are pushed to investigate further the intricacies of Ecosystem Services that will need to be replaced with technology as we approach the tipping point of planetary boundaries [2].

Definition of terms:

Form: the shape or configuration.

Form refers to the three-dimensional aspects of the thing being mimicked, the space it takes up, the way it is configured, and its internal or external structure. We would ask: what aspect of its form promotes its function?

Process: the operation of change that is performed in order to achieve a particular function.

Process describes the way in which a function is accomplished or the way in which something is produced with a consequent function. We would ask: how is it made or acquired?

Interaction: the relationship between two or more systems.

Interaction refers to the way in which exchanges occur, either of the same or different system. We would ask: how does it interact? (It should be noted here that in several of the thought experiments that have been conducted, interactions have become functions if the super-system is considered.)

In a few classification schemes, the level (or type) material has been proposed. This is inconsistent with the revised definition of biomimetics because mimicking a material by using another material would fall within the type form if it was the form of the material that was mimicked, or within process if it was the way that a material changed or was utilized that was mimicked, or within interaction if it was the way that that material related to other materials that was mimicked. A technology that simply uses a living material found in nature as part of some innovation is not specifically biomimetic but, rather, bio-assistance. 


\section{BIOMIMETICS, TYPES, AND SUSTAINABLE DEVELOPMENT}

Discussions around how best to identify the products of biomimetic activity for the purposes of promotion have often considered the incorporation of more than one type of biomimetic inspiration to be of greater value than only one type. This value has been placed largely within the lobby for Sustainable Development. (It is predicted that sustainable technologies are more often associated with bio-assistance rather than biomimetics. The framework presented here will allow this to be investigated.) A simple and elegant answer is often the most desirable, and likely more efficient, especially in fields such as engineering. Incorporating a second or third biomimetic solution may not be necessary. However, within this framework, a hierarchical scheme can now be developed to identify the actual 'Level' to which the product or activity is biomimetic.

A classification system based upon the number of types of biomimetics that are incorporated into the innovation can be developed. In this case, a technology, for example, that mimics nature in all types (Form, Process, and Interaction) would fall at a higher level than one that mimics only two types. The scheme is presented in Fig. 3. Here, all those innovations that mimic only Function are given a 0 rating, those that use 1 type are designated as 1 , and so on until level 3 . Alternatively, this scheme could be modified to allow for the use of two different mimicked forms to receive a designation of 2, for example.

This scheme will allow for the quantification of different technologies that will help to elucidate the process by which knowledge transfer occurs with respect to the types of biomimetics. Are forms more readily (easily) explored? Are processes mimicked more often in association with interactions?

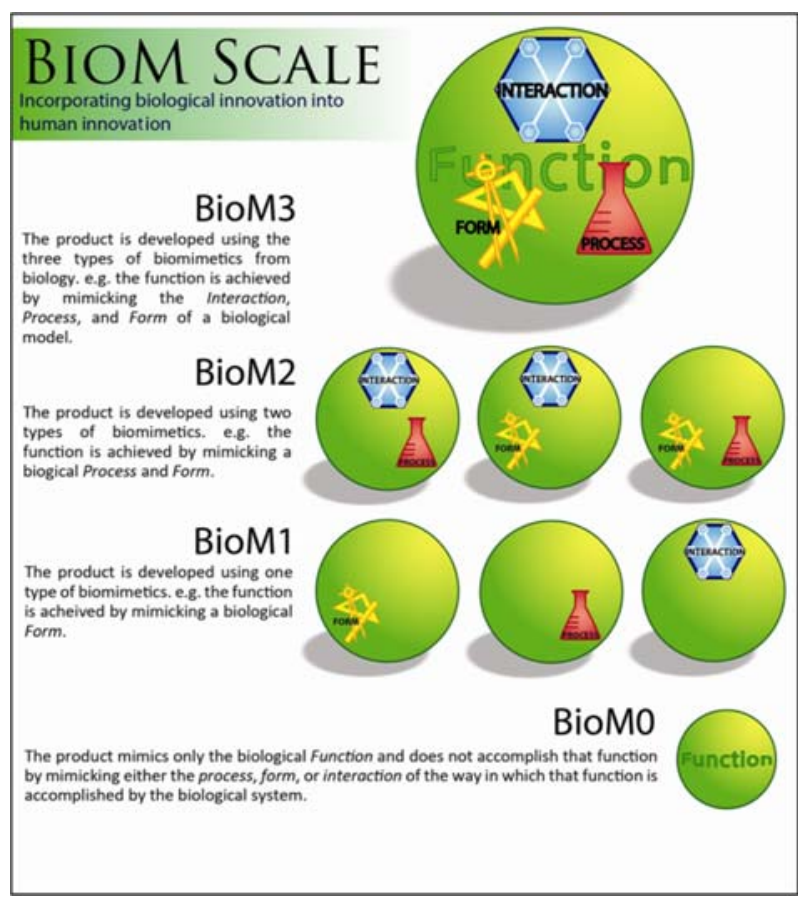

Figure 3: BioM labelling scheme. A product that mimics only Function is designated as BioM0. A product that mimics one or more types of biomimetics (Form, Process, and/or Interaction) is given a designation of BioM1-3 depending upon the number of types incorporated. 
Are biological interactions largely ignored? Understanding how biomimetics is conducted in the wild' will inform researchers developing a biomimetic process that will increase access and facilitate knowledge transfer.

Mimicking function: an example of a case that mimics function only is that of the seafloor mooring described in patent number US 7,976,245 B2. Here, the mooring technology mimics the function of a large macrophyte (kelp) in its ability to remain secured to the seabed. However, the way in which this function is accomplished does not mimic a macrophytic holdfast; it is secured with a series of anchor bolts attached to a base that is subsequently connected to the energy capturing device (for example) by a tensile transmission line.

Mimicking form: The case of Whalepower and tubercle technology is a classic example of form biomimetics. The leading edge of a humpback whale has ridges that have been shown to decrease the turbulence on the trailing edge and, therefore, increase the lift and consequent efficiency of the fin. This principle has been transferred to wind turbine technology in patent number US 6,431,498 B1. More specifically, it is the form of the humpback whale fin with its tubercles (and not the whale itself) that is being mimicked. Engineers wanting to search for further biological principles that might contribute to efficiency would likely explore the super and subsystems of the fin; both the tissue of the tubercles themselves, and the organ systems involved in operating the fin.

Mimicking process: there is increasing interest in further developing knowledge transfer from biological processes to technology. It is understood that biological processes are sustainable and are generally not detrimental to life. An interesting example is that of the technology described in US patent application 2009/0269847 A1 on self-assembling peptide amphiphiles described in more accessible detail in Palmer et al. [34]. Here, biomolecules called peptide amphiphiles are used to mimic the natural way that a collagen scaffold functions to guide bone formation.

Mimicking interaction: biological systems have evolved specific types of interactions that serve different functions. Though there are very few examples of transferring biological interactions to other disciplines, the inclusion of closed-loop industrial activities might be explored.

\section{CONCLUSION}

The need for biomimetic advancement is threefold:

1. Within natural systems, there exists an incredible bank of 'solutions' that designers have only just begun to formally investigate.

2. With the increase in negative human impacts on our planet, finding less damaging forms, processes, and interactions would reduce these impacts and could contribute to preventing the further loss of key ecosystem services.

3. Once/if we surpass the planetary tipping point, ecological services will need to be replaced by analogous technological services. This, by definition, will be only biomimetics.

Bridging engineering and biology with respect to terminology and concept has often been cited as one of the major challenges associated with biomimetic research $[9,10]$, but the gap filling should allow for bridging among a suite of fields including economics, systems science, and the social sciences if the full of potential of biomimetics is to be explored. A standardized vocabulary and solid theoretical foundation is a preliminary requirement for conducting and communicating research and for studying the way in which designers approach and interpret literature outside of their respective fields. In biomimetics, biology is being 'forced' to adapt to the conceptual 
framework of other disciplines. In doing this, a theoretical wall has been constructed upon the bridge beyond which lies the potential for further innovation. Instead, the biomimetic framework must be derived from biology before a bridge can be accessed.

If solving problems, biological or otherwise, begins with Function then, it is important to use it as a starting point, and not only another aspect to consider, or a step to explore, or another level. Within biological systems function can be achieved by Forms, Processes, and Interactions. This can now be used to identify and classify cases of biomimetic technologies to describe the types and levels of approaches to biomimetic activity, the vocabulary used to describe them, and biological models that are currently being explored.

\subsection{Future directions}

The scheme developed here will now be applied to the over 350 cases collected in the BioM Innovation Database and will be combined with information derived from detailed interviews with developers to elucidate the current practice of biomimetics.

\section{ACKNOWLEDGEMENTS}

The author thank Norbert Hoeller, Emily Nichol, Dan Gussin, Marc Pritchard, and Tarik Chekchak for many and lengthy conversations on the topic. SJ benefitted from funds provided by the Silicon Valley Community Foundation and the Sustaining Design Fund of Tides Canada Foundation.

\section{REFERENCES}

[1] Crutzen, P.J., Geology of mankind. Nature 415, p. 23, 2002. doi: http://dx.doi. org/10.1038/415023a

[2] Rockstrom, J., Steffen, W., Noone, K., Persson, A. \& Chapin, F.S., Planetary boundaries: exploring the safe operating space for humanity. Ecology and Society, 14, p. 32, 2009.

[3] Stern, N., The Economics of Climate Change: The Stern Review, Cambridge University Press: Cambridge, 2007.

[4] Gleich, A.V., Pade, C., Petscho, U. \& Pissarskoi, E., Potentials and Trends in Biomimetics, Springer: Heidelberg, 2010.

[5] Vincent, J.F.V., Bogatyreva, O.A., Bogatyrev, N.R., Bowyer, A. \& Pahl, A.-K., Biomimetics: its practice and theory. Journal of Royal Society Interface, 3, pp. 471-482, 2006. doi: http:// dx.doi.org/10.1098/rsif.2006.0127

[6] Gruber, P., Biomimetics in Architecture, Springer Wien: New York, 2011. doi: http://dx.doi. org/10.1007/978-3-7091-0332-6

[7] Pedersen Zari, M., Biomimetic approaches to architectural design for increased sustainability. Sustainable Building Conference, Auckland, 2007.

[8] Bonser, R.H.C. \& Vincent, J.F.V., Technology trajectories, innovation, and the growth of biomimetics. Proc. IMechE, 221, pp.1177-1180, 2007.

[9] Steele, J., How do we get there? Bionics Symposium: Living prototypes - The Key to New Technology, Wright-Patterson Air Force Base, Ohio, Wright Air Development Division, 1960.

[10] Bar-Cohen, Y., Biomimetics: mimicking and inspired-by biology. Proceedings of the SPIE Smart Structures Conference, San Diego, SPIE, 2005.

[11] Bhushan, B., Biomimetics: lessons from nature - an overview. Philosophical Transaction of the Royal Society London, Series A, 367, pp. 1445-1486, 2009. doi: http://dx.doi.org/10.1098/ rsta.2009.0011 
[12] Harkness, J.M., In appreciation: a lifetime of connections: Otto Herbert Schmitt, 1913-1998. PIP, 4, pp. 456-490, 2002.

[13] Anonymous, Science, 132, 1960.

[14] Van Bergeijk, W.A., Nomenclature of devices which simulate biological functions. Science, 132, pp. 1248-1249, 1960. doi:doi: http://dx.doi.org/10.1126/science.132.3435.1248

[15] Vincent, J.F.V., Biomimetics - a review. Proc. IMechE, 223, pp. 919-939, 2009. doi: http:// dx.doi.org/10.1243/09544119JEIM561

[16] Dargent, E., Biomimicry for Business? MBA Thesis. Business Administration, University of Exeter, 2011.

[17] Vogel, S., Cats' Paws and Catapults, WW Norton \& Co: New York, 1998.

[18] Schmitt, O.H., Where are we now and where are we going? Bionics Symposium: Living Prototypes - The Key to New Technology, Wright-Patterson Air Force Base, Ohio, Wright Air Development Division, 1960.

[19] Taube, M., What good is bionics? Bionics Symposium: Living Prototypes - The Key to New Technology, Wright-Patterson Air Force Base, Ohio, Wright Air Development Division, 1960.

[20] Nachtigall, W., Vorbild Natur. Bionik - Design für funktionelles Gestalten. Springer: Berlin, 1997.

[21] Oxford Dictionary, 2008.

[22] Ataide, R., The Global Biomimicry Efforts: An Economic Game Changer, Fermian Business and Economic Institute, 2010.

[23] Nieuwenhuis, P. \& Lammgard, C., Expanding industrial ecology's ecological metaphor - an historical perspective. International Greening of Industry Network Conference, Seoul, 2010.

[24] Benyus, J.M., Biomimicry: Innovation Inspired by Nature, Harper: New York,1997.

[25] Hartwell, H.L., Hopfield, J.J., Leibner, S. \& Murray, A.W., From molecular to modular cell biology. Nature, 402, pp. 47-52, 1999. doi: http://dx.doi.org/10.1038/35011540

[26] Bellomo, N., Modeling Complex Living Systems: A Kinetic Theory and Stochastic Game Approach. Birkhauser: Boston, 2008.

[27] Interface LLC 2012. www.interface.com

[28] Likens, G.E., Bormann, F.H., Johnson, N.M. \& Pierce, R.S., The calcium, magnesium, potassium, and sodium budgets for a small forested ecosystem. Ecology, 48, pp. 772-785, 1967. doi: http://dx.doi.org/10.2307/1933735

[29] Gosz, J.R., Likens, G.E. \& Bormann, F.H., Organic matter and nutrient dynamics of the forest and the forest floor in the Hubbard Brook Forest. Oecologia, 22, pp. 305-320, 1976. doi: http:// dx.doi.org/10.1007/BF00345310

[30] Condit, R., Ashton, P., Baker, P., Bunyavejchewin, S., Gunatilleke, S., Gunatilleke, N., Hubbell, S., Foster, R., Itoh, A., LaFrankie, J. et al., Spatial patterns in the distribution of tropical tree species. Science, 288, pp. 1441-1418, 2000. doi: http://dx.doi.org/10.1126/science.288.5470.1414

[31] Paluch, J., The influence of the spatial pattern of trees on forest floor vegetation and silver fir (Abies alba Mill.) regeneration in uneven-aged forests. Forest Ecology and Management, 205, pp. 283-298, 2005. doi: http://dx.doi.org/10.1016/j.foreco.2004.10.010

[32] Solomon, E.P., Berg, L.R. \& Martin, D.W., Biology, Brooks/Cole, 2002.

[33] Biomimicry 3.8 2012. www.biomimicry.net

[34] Palmer, L.C., Newcomb, C.J., Kaltz, S.R., et al., Biomimetic systems for hydroxyapatite mineralization inspired by bone and enamel. Chemical reviews, 108, pp. 4754-4783, 2008. doi: http://dx.doi.org/10.1021/cr8004422 